This item was submitted to Loughborough's Research Repository by the author.

Items in Figshare are protected by copyright, with all rights reserved, unless otherwise indicated.

\title{
Spontaneous emulsification of water in oil at appreciable interfacial tensions
}

PLEASE CITE THE PUBLISHED VERSION

http://dx.doi.org/10.1016/j.colsurfa.2016.05.041

\section{PUBLISHER}

(c) Elsevier

\section{VERSION}

AM (Accepted Manuscript)

\section{PUBLISHER STATEMENT}

This work is made available according to the conditions of the Creative Commons Attribution-NonCommercialNoDerivatives 4.0 International (CC BY-NC-ND 4.0) licence. Full details of this licence are available at: https://creativecommons.org/licenses/by-nc-nd/4.0/

\section{LICENCE}

CC BY-NC-ND 4.0

\section{REPOSITORY RECORD}

Silva, Pedro T. Santos, Sergey Zhdanov, Victor Starov, and R.G. Holdich. 2016. "Spontaneous Emulsification of Water in Oil at Appreciable Interfacial Tensions". figshare. https://hdl.handle.net/2134/22273. 
Elsevier Editorial system(tm) for Colloids and Surfaces A: Physicochemical and Engineering Aspects

Manuscript Draft

Manuscript Number: COLSUA-D-16-00714R1

Title: Spontaneous Emulsification of Water in Oil at Appreciable Interfacial Tensions

Article Type: SI: Victor_Starov

Keywords: spontaneous emulsification, w/o emulsions, interfacial tension, Span® 80

Corresponding Author: Prof. Victor Starov, MSc, PhD, DSC

Corresponding Author's Institution: Loughborough University

First Author: Pedro Silva

Order of Authors: Pedro Silva; Sergey Zhdanov, Dr; Victor Starov, MSc, PhD, DSc; Richard Holdich, Dr

Manuscript Region of Origin: UNITED KINGDOM

Abstract: Spontaneous formation of aqueous droplets in kerosene was observed, which was facilitated by the presence of an oil soluble surfactant: Span® 80 at concentrations above CMC. Kerosene/water interfacial tension under all conditions studied was not lower than 4 $\mathrm{mN} / \mathrm{m}$. Therefore, ultra-low interfacial tension was not required for this process to occur spontaneously. The process was caused by a transfer of water molecules to swollen reversed micelles. The influence of both the surfactant concentration in the organic phase and NaCl concentration in the aqueous phase on spontaneous aqueous droplet formation was investigated. Nano-sizing analyse of the drops was performed, which showed the droplets sizes in between 100 and $400 \mathrm{~nm}$. It is proven that the presence of salt in the aqueous phase inhibits droplet formation. It is shown that big sessile aqueous droplets deposited on a hydrophobic substrate inside the kerosene phase were dissolved in kerosene through formation and growth of droplets, which form an aqueous film at the droplet base. 
Graphical Abstract

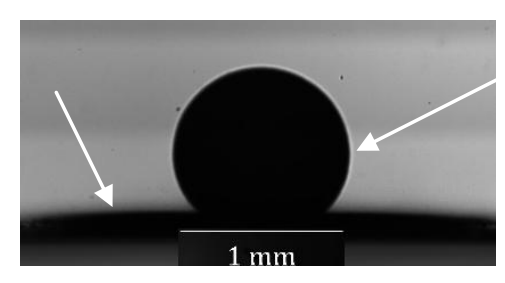

$1 \mathrm{~h}$
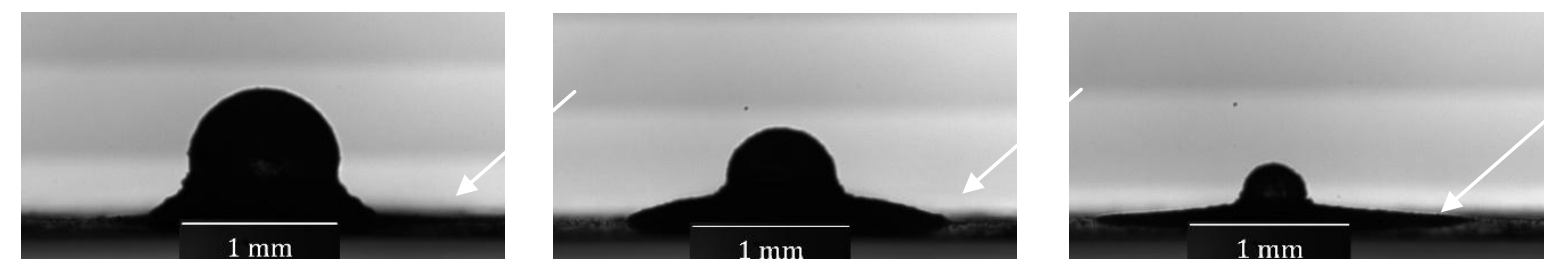

$8 \mathrm{~h}$

$22 \mathrm{~h}$

$48 \mathrm{~h}$ 
${ }^{*}$ Highlights (for review)

\section{Highlights}

Spontaneous formation of aqueous droplets in kerosene

High kerosene/water interfacial tension

Sessile aqueous droplets were dissolved in kerosene 


\title{
Spontaneous Emulsification of Water in Oil at Appreciable Interfacial Tensions
}

Pedro S. Silva ${ }^{1 \mathrm{a}}$, Sergey Zhdanov ${ }^{2 \mathrm{~b}}$, Victor M. Starov ${ }^{1 \mathrm{c}}$, Richard G. Holdich ${ }^{1 * \mathrm{~d}}$

${ }^{1}$ Department of Chemical Engineering, Loughborough University, Loughborough, LE11 3TU, UK.

${ }^{2}$ Micropore Technologies Ltd, T-366, Wilton Centre, Redcar, TS10 4RF

ap.t.santos-silva@lboro.ac.uk, bs.zhdanov@micropore.co.uk, cv.m.starov@lboro.ac.uk, ${ }^{\mathrm{d}}$ r.g.hodich@lboro.ac.uk

\begin{abstract}
Spontaneous formation of aqueous droplets in kerosene was observed, which was facilitated by the presence of an oil soluble surfactant: $\operatorname{Span}^{\circledR} 80$ at concentrations above CMC. Kerosene/water interfacial tension under all conditions studied was not lower than 4 $\mathrm{mN} / \mathrm{m}$. Therefore, ultra-low interfacial tension was not required for this process to occur spontaneously. The process was caused by a transfer of water molecules to swollen reversed micelles. The influence of both the surfactant concentration in the organic phase and $\mathrm{NaCl}$ concentration in the aqueous phase on spontaneous aqueous droplet formation was investigated. Nano-sizing analyse of the drops was performed, which showed the droplets sizes in between 100 and $400 \mathrm{~nm}$. It is proven that the presence of salt in the aqueous phase inhibits droplet formation. It is shown that big sessile aqueous droplets deposited on a hydrophobic substrate inside the kerosene phase were dissolved in kerosene through formation and growth of droplets, which form an aqueous film at the droplet base.
\end{abstract}


Key words: spontaneous emulsification, osmotic pressure, interfacial tension, $\operatorname{Span}^{\circledR} 80$.

\section{Introduction}

Emulsions consist of a discontinuous phase (droplets), a continuous phase (liquid surrounding the droplets) and an interface where surfactants are usually present, lowering the interfacial tension and, therefore, decreasing the free energy for formation and stabilizing the two phase system. Energy input is required, generally mechanical, to disperse the discontinuous phase in the continuous phase and to create the additional interfacial area. The Gibbs free energy increase of the system $(\Delta \mathrm{G})$, at constant composition and pressure after mixing is as follows:

$$
\Delta G=\gamma \Delta A-T \cdot \Delta S
$$

where $\Delta \mathrm{S}$ is an entropy increase, $\Delta \mathrm{A}$ is the increase of the interface, $\mathrm{T}$ is temperature in Kelvin and $\gamma$ is an interfacial tension.

For the spontaneous formation of emulsions $\Delta \mathrm{G}$ should be negative, hence, the interfacial tension $(\gamma)$ should is very low [1].

The extent of surfactant adsorption at a liquid surface is expressed in terms of its surface excess concentration, $\Gamma$. Surface excess concentration is related to surface tension by the Gibbs equation, which for a non-ionic surfactant takes the form [2]:

$$
\Gamma=-\frac{c}{R T} \frac{d \gamma}{d c}=-\frac{1}{R T}\left(\frac{d \gamma}{d \ln c}\right)_{S}
$$

where $\mathrm{c}$ is the surfactant concentration. It becomes possible to estimate the area occupied by each adsorbed surfactant molecule at known $\Gamma[2]$.

Microemulsions are an example of thermodynamically stable and macroscopically homogeneous mixtures of water, oil and surfactant. They form spontaneously and they are 
characterised by ultra-low interfacial tension $(<0.1 \mathrm{mN} / \mathrm{m})$ between water and oil, thus minimising the required amount of energy to form the new surface area as shown in Eq (1). Microemultions can be opaque or transparent depending on the size and concentration of droplets in the emulsion. In the case of ultralow interfacial tension this type of emulsification does not require energy input, as the ultralow interfacial tension leads to a spontaneous emulsification when the phases are brought in contact [1]. The full mechanism behind this phenomenon is still under investigation and is a matter for discussion despite the fact that microemulsions were first recorded in the XIX century [3-10].

Spontaneous formation of a new type of emulsions in the presence of relatively high surfactant concentration and high enough interfacial tension was earlier discovered [11]. According to Shinoda and Kunieda [11] this systems were erroneously considered as microemulsions, however, they are "solubilized solutions" and for such systems "swollen micellar solution" may be a more adequate term [11]. Usually, very large concentrations (10$25 \% \mathrm{w} / \mathrm{w}$ ) of a non-ionic surfactant are required to produce these so-called microemulsions $[11,12]$. Solubility of water in hydrocarbons and vice versa has been studied extensively due to the high interest that energy industry has. Equations of state have been used to describe mutual solubility of water and several types of hydrocarbons in a wide range of pressures and temperature $[13,14]$.

Below spontaneous formation of water in oil (w/o) emulsion, at sufficiently high interfacial tension in the presence of high concentration of oil soluble surfactant is investigated. From the very beginning it was understood that such microemulsions are actually swollen reverse micelles [11].

Control of spontaneous emulsification might be important in a numbers of applications where there is a demand for nano-sized droplets in an emulsion such as in personal care, cosmetics and health, care industry [15]. Alternatively, this process might be 
undesirable. An excess of surfactant is commonly used in a semi-batch process where the amount of disperse phase increases with time and an "over use" of surfactant takes places in order to avoid the depletion of surfactant at the end of the process. The existence of this spontaneous process should be taken in to consideration in processes where the main goal is to have great control over the droplet size and size distribution (e.g. in membrane emulsification). Processes operated over a long period of time can be more vulnerable.

An interesting possible application of spontaneous microemulsions is the fuel industry, there is an interest in (w/o) emulsions, which can play a substantial role in reducing emissions and improving engine performance: diesel fuel emulsions have been shown to reduce $\mathrm{NO}_{\mathrm{x}}$, $\mathrm{CO}$, soot, hydrocarbons and particulate matter emissions when used in a compression ignition engine [16], and better overall efficiency [17]. In the production of uniform particles there are a number of w/o processes where hydrogel particles are formed by dispersing an aqueous phase into an oil phase, typically low odour kerosene, using membrane emulsification to form uniform droplets and, therefore, particles after reaction [18]. This reaction is often a condensation polymerisation in which water is one of the reaction products, thus nano-sized emulsion drops become evident during the reaction often detected as a cloudy haze.

The spontaneous process reported below was performed using sessile droplet experiments where a single big water drop (surrounded by the organic phase) was monitored. In order to confirm the presence of aqueous nano-droplets in the organic phase, with a varying concentration of oil soluble surfactant, a set of experiments were designed to evaluate the drop size and concentration at equilibrium conditions using a nano-droplet tracking analysis characterisation technique. Kerosene was chosen as the organic phase because it is both an example of a common fuel and it is used in a number of emulsification processes [18] for hydrogel particles. 


\section{Materials and methods}

Sessile droplet experiments were carried out to monitor time evolution of aqueous droplet height, radius and dynamic contact angle. The experiments were performed using a custom-built experimental setup, which is presented in Figure 1. The substrate used was a 316 stainless steel (SS) sheet $(0.1 \times 25 \times 25 \mathrm{~mm})$ purchased from GoodFellow Ltd. The substrates were chemically hydrophobically coated. The cleaning of the substrate consisted of placing the SS sheets in an organic solvent (methanol and/or acetone) followed by drying at $40-50^{\circ} \mathrm{C}$ for at least 30 minutes before the start of a new experiment. A DMK 23G $445 \mathrm{GigE}$ monochrome industrial camera (Imaging source, Germany), coupled with Bi-telecentric lenses (OPTO Engineering, Italy), was used for monitoring the side view of the droplet. On the opposite side a light source was mounted parallel to the camera - telecentric HP Illuminator (OPTO Engineering, Italy) as shown schematically in Figure 1.

The experimental protocol was as follows: a water droplet was deposited on the hydrophobic SS sheet which was surrounded by the organic phase (kerosene). The volume used of organic phase was about $20 \mathrm{~mL}$, contained in a glass chamber of 40x40x30 mm. During experiments the chamber was covered in order to avoid dust deposition. The drop deposition was performed using a micro-syringe $(500 \mu \mathrm{L})$ mounted in a support designed to improve the drop placement accuracy.

The organic phase was low odour kerosene purchased from Sigma Aldrich. The surfactant $\operatorname{Span}^{\circledR} 80$, purchased from Sigma Aldrich, was dissolved in the organic phase. This surfactant includes a sorbitol group (hydrophilic head) and a long unsaturated carbon chain (hydrophobic tail) and is commonly used to stabilise w/o emulsions. Its chemical structure is shown in Figure 2. 


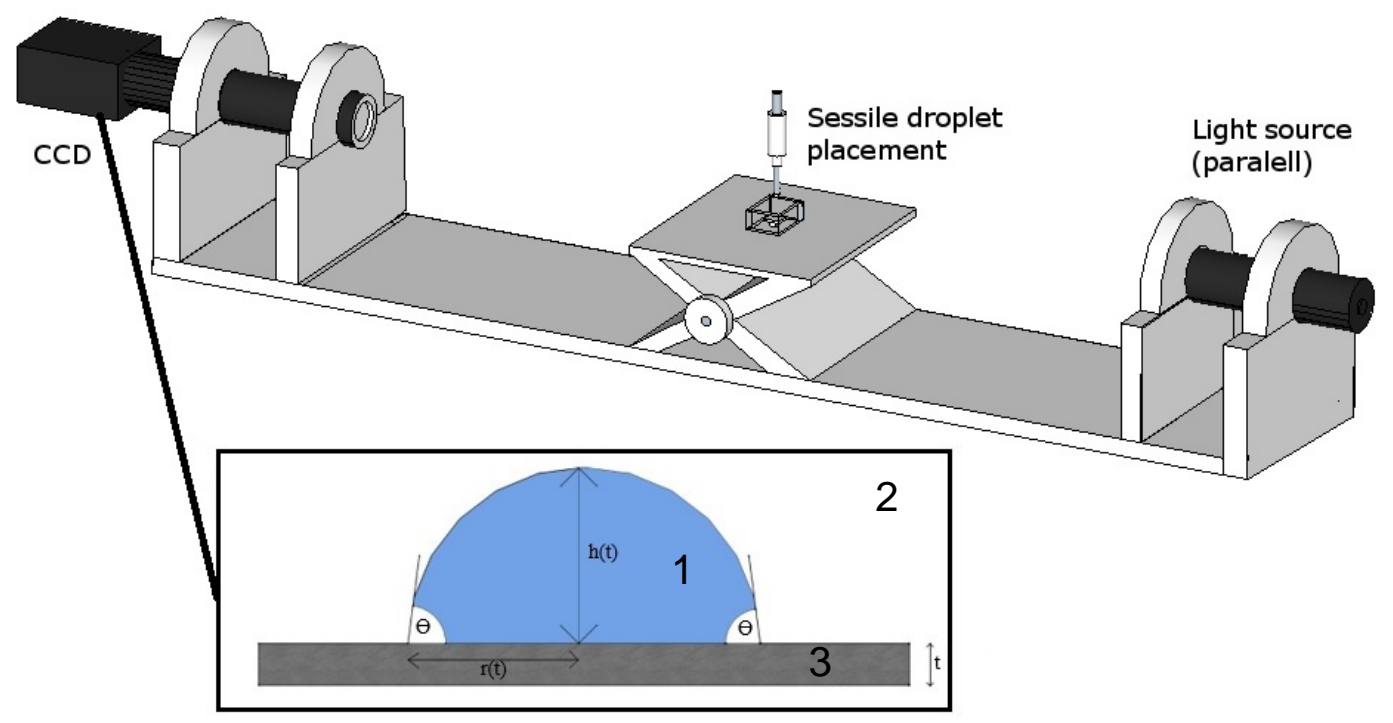

Figure 1. Diagram of the experimental set up for sessile droplet experiments: 1 - aqueous droplet with (or without) added salt; 2 - organic phase with (or without) Span ${ }^{\circledR} 80$ surfactant, 3 - hydrophobic support

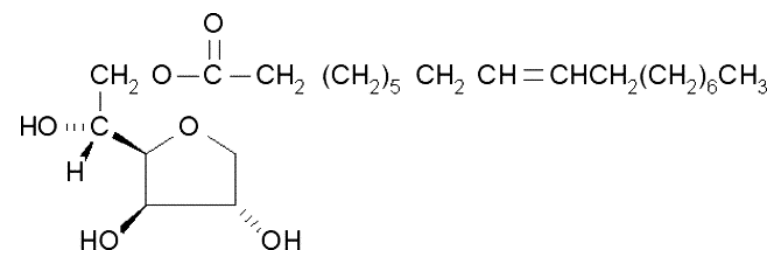

Figure 2. The chemical structure of surfactant $\operatorname{Span}{ }^{\circledR} 80$

Image analysis was undertaken using a computer application of Vision Builder from LabView (National Instruments). The software was designed to acquire the following measurements of the droplet: height $(\mathrm{h})$, contact angle $(\Theta)$ and radius $(\mathrm{r})$ of the droplet base. So the drop volume (V) could be determined using well-known equations (3) or (4). The two equations allow calculating the droplet volume in two different ways. These two different ways of calculation of the drop volume were compared in order to evaluate the image analysis reliability, estimating the measurement error. The drop volume was normalised according to Eq. (5). The droplet was formed in the organic phase with surfactant (Figure 1). 
Various amounts of surfactant used in the system changed the interfacial tension, up to the Critical Micelle Concentration (CMC). However, the spontaneous droplet formation was observed only at concentration above CMC, which resulted in different droplet sizes.

Drop volume was determined using measured values of height (h) and radius of the base (r):

$$
V=\frac{\pi h}{24}\left(3 r^{2}+h^{2}\right)
$$

Alternatively the drop volume was also determined using measured values of the radius of the base $(r)$ and contact angle $(\Theta)$ :

$$
V=\frac{\pi r^{3}}{3}\left(\frac{2-3 \cos (\theta)+\cos ^{3}(\theta)}{\sin ^{3} \theta}\right)
$$

The reduced droplet volume was calculated according to the following equation:

$$
V_{n}=\frac{V(t)}{V_{0}}
$$

Additional to the sessile droplets experiments, another procedure was used in order to gain extra information on the system under investigation. Six solutions of an aqueous phase with different $\mathrm{NaCl}$ concentrations $(0 \%, 0.1 \%, 1 \%, 2 \%, 5 \%$ and $10 \% \mathrm{w} / \mathrm{w})$ and four kerosene solutions with different $\operatorname{Span}^{\circledR} 80$ concentrations were prepared. In each $10 \mathrm{~mL}$ of kerosene Span $^{\circledR} 80$ solutions were added to $10 \mathrm{~mL}$ of aqueous $\mathrm{NaCL}$ solutions and left undisturbed in hermetically closed vials (clear glass $28 \mathrm{~mL}$ capacity) for several hours. In total 24 vials were prepared in such a way. After reaching equilibrium by both phases the presence of water droplets in the organic phase was checked, and the concentration and size of droplets were determined using a NanoSight LM10 (NanoSight/Malvern, Amerbury, United Kingdom), equipped with a sample chamber with a 640-nm laser and a Viton fluroelastomer O-ring. The device was using Nano-particle Tracking Analysis (NTA) software. The samples were injected in to the sample chamber with sterile $(5 \mathrm{~mL})$ plastic syringes (BD Discardit $\left.{ }^{\circledR} \mathrm{II}\right)$ until 
the liquid reached the tip of the nozzle. All measurements were carried out at room temperature $25^{0}$ C. NTA 3.0 software was used for capturing and analysing the data. Samples were measured for 60 seconds with manual shutter and gain adjustments. Five measurements of each sample were repeated and the averaged values were used.

Interfacial tension measurements were carried out using the DCAT11 tensiometer from DataPhysics using the Wilhelmy-plate method. Prior to each measurement, the platinum plate was cleaned using a burner to remove all organic traces. To determine the CMC the surfactant concentration in the kerosene was subsequently increased while measuring interfacial tension between the kerosene and pure water.

\section{Results and discussion}

\subsection{Characterization of the water droplets present in the organic phase}

The influence of both salt concentration in the aqueous phase and surfactant concentration of $\operatorname{Span}{ }^{\circledR} 80$ in the organic phase of spontaneous formation of aqueous droplets in kerosene was investigated.

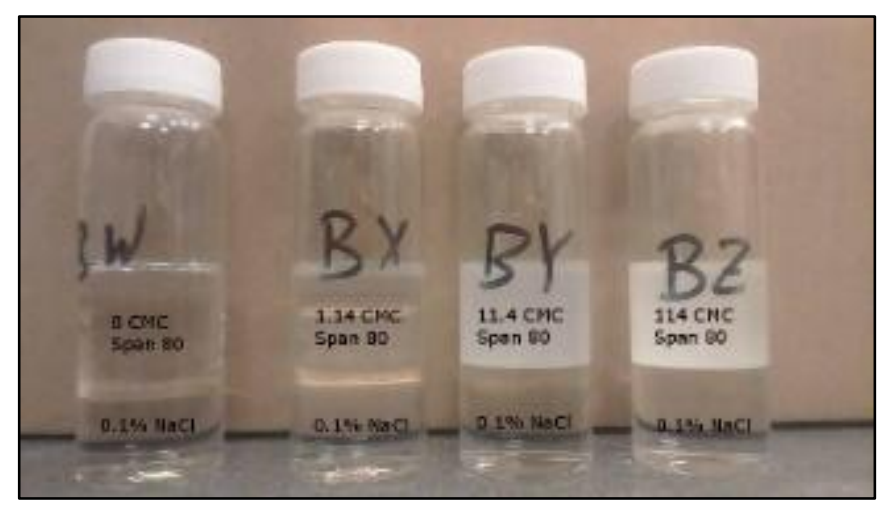

Figure 3. Example of the surfactant concentration influence on the self-emulsification process: each vial contains $10 \mathrm{~mL}$ of water (lower liquid layer) and $10 \mathrm{~mL}$ of kerosene (top liquid layer) with different concentration of $\mathrm{Span}^{\circledR}$ 80: samples BW, BX, BY and BZ contain pure water, 1.4, 11.4 and 114 times the $\mathrm{CMC}$, respectively. There is no visible detection of microemulsion formation in vials BW and BX, but they are present in vials BY and BZ. 
Figure 3 shows that microemulsions were formed only if the concentration of micelles in the kerosene was higher than some critical value, which is according to our experimental results either equal to $\mathrm{CMC}$ or slightly above $\mathrm{CMC}$. Observations performed during the experiments indicated that the turbidity in the organic phase was clearly influenced by the amount of surfactant present (Figure 3). Influence of salt concentration in the aqueous phase on the microemulsion formation was also investigated. These experiments proved that the higher salt concentration in the aqueous phase the lower turbidity becomes (or low concentration of droplets inside the kerosene). Below characterization of this process was carried out, using NTA size analysis: concentration of the aqueous microdroplets and their size was determined.

Tables 1 and 2 summarise the data collected from these experiments. Higher concentration of surfactant promotes the self-emulsification of water in kerosene, while higher concentration of salt retards, or even stops, this phenomenon from happening.

Table 1 Droplet concentration with salt and surfactant concentration on the spontaneous formation of aqueous droplets in kerosene

\begin{tabular}{|c|c|c|c|c|}
\hline $\begin{array}{c}\text { Concentration of } \\
\mathrm{NaCl}\end{array}$ & \multicolumn{5}{|c|}{ Concentration of drops (number/mL) at the following CMC values: } \\
\hline$(\% \mathbf{w} / \mathbf{w})$ & $\mathbf{0 x}$ & $\mathbf{1 . 1 4 \times}$ & $\mathbf{1 1 . 4 \times}$ & $\mathbf{1 1 4 x}$ \\
\hline 0 & 0 & $6.0 \times 10^{8}$ & $2.5 \times 10^{12}$ & $7.0 \times 10^{12}$ \\
\hline 0.1 & 0 & 0 & $1.19 \times 10^{12}$ & $3.5 \times 10^{12}$ \\
\hline 1 & 0 & 0 & $2.7 \times 10^{8}$ & $1.9 \times 10^{11}$ \\
\hline 2 & 0 & 0 & $7.6 \times 10^{8}$ & $1.2 \times 10^{11}$ \\
\hline 5 & 0 & 0 & $7.05 \times 10^{8}$ & $9.1 \times 10^{10}$ \\
\hline 10 & 0 & 0 & $2.5 \times 10^{8}$ & $1.1 \times 10^{10}$ \\
\hline
\end{tabular}


Table 2. Aqueous droplet size with salt concentration in the aqueous phase and surfactant concentration in the organic phase

\begin{tabular}{|c|c|c|c|c|}
\hline $\begin{array}{c}\text { Concentration of } \\
\mathrm{NaCl}\end{array}$ & \multicolumn{5}{|c|}{ Drop size (nm) at the following CMC values: } \\
\hline$(\% \mathbf{w} / \mathbf{w})$ & $\mathbf{0 x}$ & $\mathbf{1 . 1 4 x}$ & $\mathbf{1 1 . 4 x}$ & $\mathbf{1 1 4 x}$ \\
\hline 0 & 0 & 226 & 190 & 320 \\
\hline 0.1 & 0 & 0 & 190 & 290 \\
\hline 1 & 0 & 0 & 230 & 210 \\
\hline 2 & 0 & 0 & 210 & 270 \\
\hline 5 & 0 & 0 & 220 & 240 \\
\hline 10 & 0 & 0 & 420 & \\
\hline
\end{tabular}

The data presented in Table 1 shows that the concentration of drops formed in the organic phase decreases rapidly with increasing of salt concentration. In the absence of any salt in the aqueous phase the maximum water drop concentration reaches $7.0 \times 10^{12}$ drops per $\mathrm{mL}$, when using a Span 80 concentration 114 times that of the CMC value. Table 2 illustrates a wide range of droplet sizes found in the samples that contained aqueous droplets in the organic phase, but the reported drop sizes are generally between 200 and 300 nanometres.

The data suggests that self-emulsification does not occur when the surfactant concentration is below the $\mathrm{CMC}$ and that even a very low concentration of salt will stop the self-emulsification process when operating at a surfactant concentration close to the CMC. When operating at a surfactant concentration of 114 times CMC then 200 to 300 nanometre aqueous drops were formed at all concentrations of salt used in the aqueous phase, but with much reduced resulting drop concentration at increasing salt concentration. 


\subsection{Sessile droplets experiments}

According to the procedure described above (two ways of calculations of the droplet volume) the experimental error in the drop volume calculations is less than $7 \%$. Experiments on time evolution of aqueous droplets deposited on a hydrophobic substrate surrounded by an organic phase (kerosene) with a high amount of surfactant $\left(\operatorname{Span}^{\circledR} 80\right)$ in the organic phase are reported in this section. The concentration of surfactant used was 114 times above the CMC. 5 seconds after placing the water drop on the hydrophobic substrate (SS), some cloudiness was observed at the bottom of the droplet (Figure 4a). After 125 seconds (Figure $4 \mathrm{~b})$, the cloudiness became more visible and a film started to form on the substrate in the vicinity of the three phase contact line. After around 1 hour (Figure 4d), the film became large enough to be observed using the top camera. The film had a circular shape around the droplet base and its diameter increased with time. It was observed after $8 \mathrm{~h}$ that the main droplet was becoming noticeably smaller and the film thicker with time. Hence, during this experiment spontaneous emulsification was happening over a prolonged period of time, transferring water from the main drop to the surrounding film via microemulsion droplets within the continuous phase (kerosene).
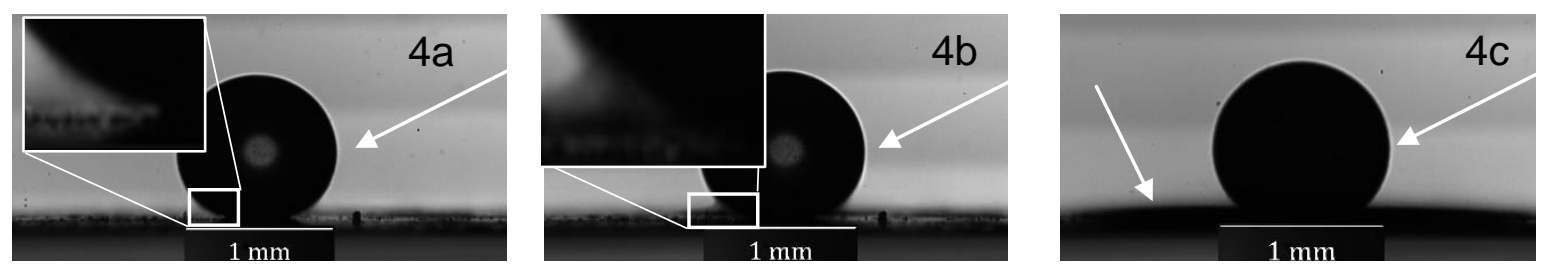

$\mathrm{t}_{1}=5 \mathrm{~s}$

$\mathrm{t}_{2}=125 \mathrm{~s}$

$\mathrm{t}_{3}=1 \mathrm{~h}$ 


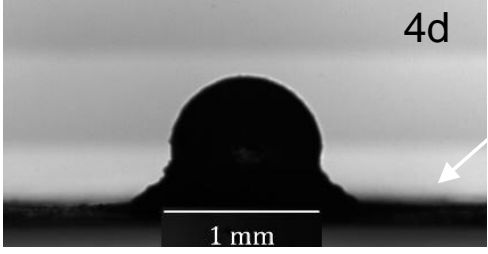

$\mathrm{t}_{4}=8 \mathrm{~h}$

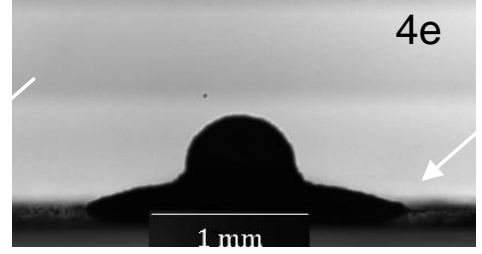

$\mathrm{t}_{5}=22 \mathrm{~h}$

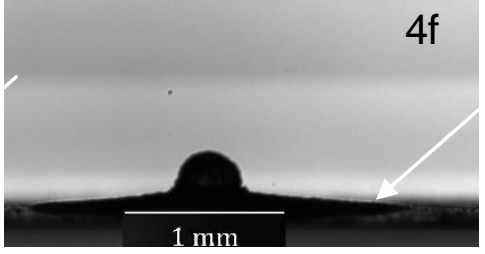

$\mathrm{t}_{6}=48 \mathrm{~h}$

Figure 4. Formation of a cloud of nano-sized droplets and a film at the droplet base assisted by swollen micelles present in the organic phase (kerosene)

The critical micelle concentration of $\mathrm{Span}^{\circledR} 80$ in kerosene was determined by interfacial tension measurements, and found to be $0.51 \pm 0.07 \mathrm{mM}$. The interfacial tension between water and kerosene at the $\mathrm{CMC}$ is $4.0 \pm 0.1 \mathrm{mN} / \mathrm{m}$. This value agrees well with the literature data [19]. According to Peltonen measurements [20] this surfactant apparently has higher interfacial tension at the CMC using a pure alkane (hexane) instead of a mixture of alkanes and some residual aromatics hydrocarbons present in the low odour kerosene.

The water drop volume behaviour for four different $\operatorname{Span}^{\circledR} 80$ concentrations was also investigated. The phenomenon described above (film formation around the droplet base) was only observed when $\operatorname{Span}^{\circledR} 80$ concentrations used was above 11.4 CMC. After a certain time contact angle could not be measured anymore due to the presence of the surrounding water film. Therefore, the volume on time dependences presented in Figure 5 were determined using just the height of the droplet and assuming that radius of the droplet was constant.

It can be seen in Figure 5 that the decrease of the drop volume is faster when the number of micelles in the organic phase is higher. This implies that the mass transfer of water in the organic phase is influenced by the presence of reverse micelles. The decrease of volume of aqueous droplet shows a linear behaviour when surfactant is not present in organic phase. The rate $(\mathrm{dV} / \mathrm{dt})$ determined is this case was $1.8 \mathrm{~nL} / \mathrm{h}$. However, in presence of 
surfactants above the critical concentration (11.4 and 114 times its $\mathrm{CMC}$ ), the water drop volume decreases logarithmically.

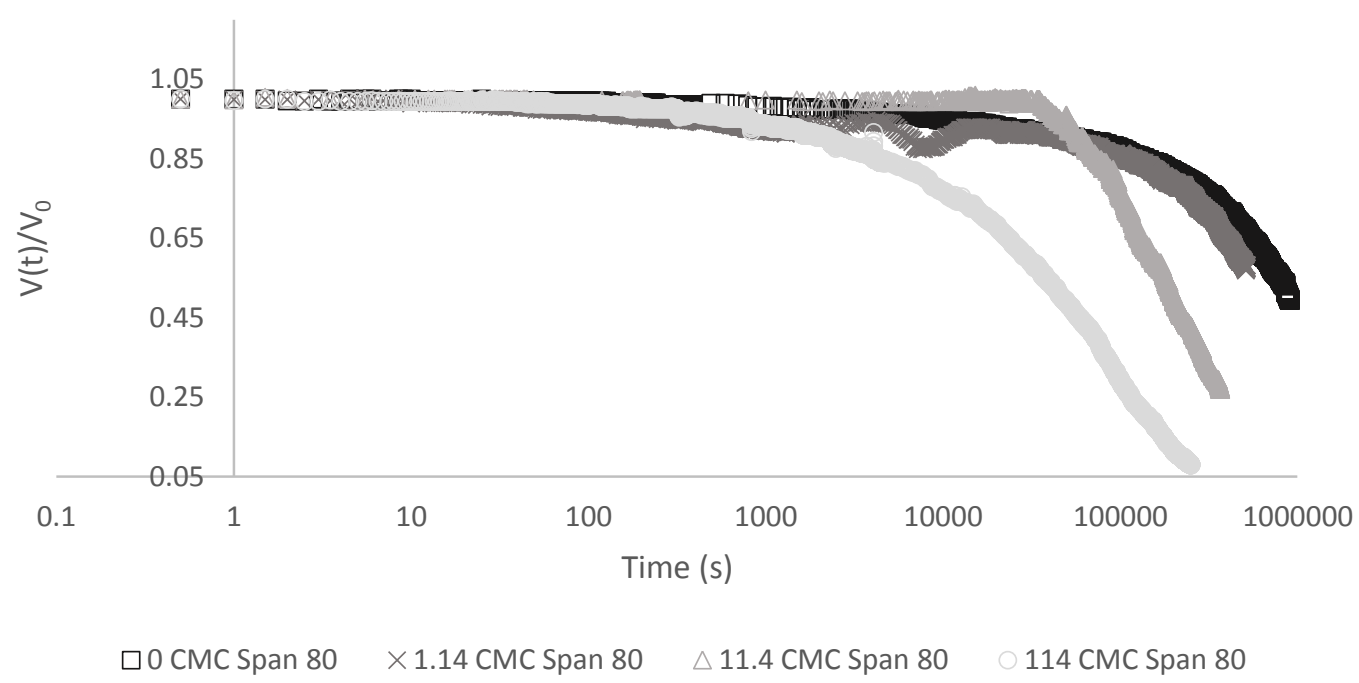

Figure 5. Higher concentrations of surfactant, present in the surrounding phase promotes the faster shrinking of the water drop, speeding up the mass transfer of water from the drop to the surrounding phase.

In this system the reverse micelles solubilise water molecules and transfer through the organic phase. The micelles swell over time and, eventually become large enough to scatter light and to sink to form the film of water around the main water drop. The process is shown schematically in Figure 6.

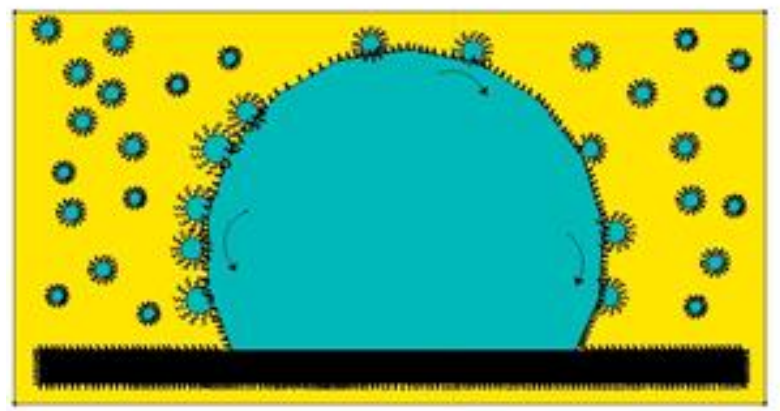


Figure 6. Schematic representation of spontaneous emulsification being driven by the swollen micelles

As soon as the water molecules "escape" from the droplet they are surrounded by the micelles which solubilise them and swell. Due to the buoyancy effect, these swollen micelles roll down to the bottom forming a film. Different salt concentrations were tested in the aqueous phase. According to part 3.1 the increased salt concentration should inhibit the mass transfer of water into the organic phase. A range of $\mathrm{NaCl}$ concentrations in the aqueous drop was investigated, the results are shown in Figure 7.

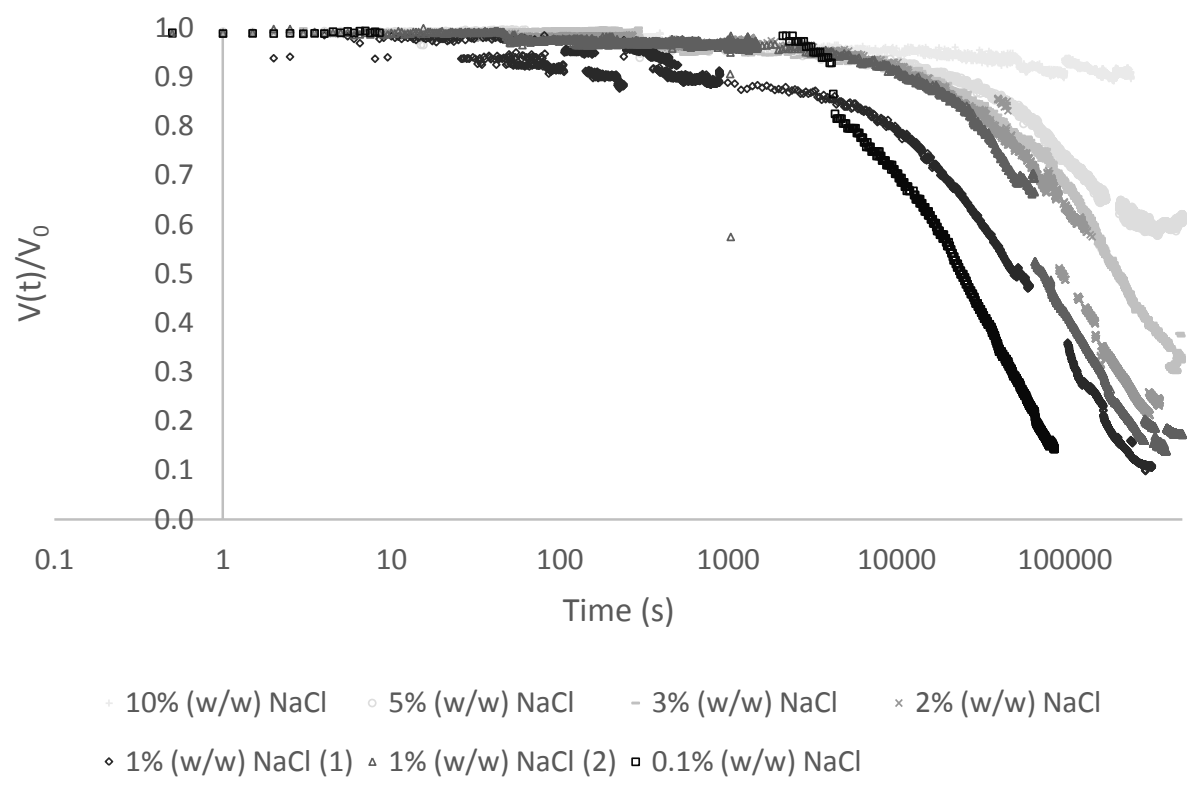

Figure 7. Influence of salt in the aqueous phase on the drop volume evolution

Figure 7 shows that different concentrations of $\mathrm{NaCl}$ in the water phase have a clear influence on the transfer of water molecules to swollen micelles. Higher concentrations of salt slow down the transfer process. At a concentration of $10 \%(\mathrm{w} / \mathrm{w}) \mathrm{NaCl}$ the droplet barely changes its volume for almost 250000 seconds (70 hours). It is important to note that during 
mass transfer the salt concentration in the water droplet increases over time which explains the non-linear behaviour of the droplet volume shrinking with time for lower ratios of CMC.

\section{Conclusions}

Spontaneous formation of aqueous microdroplet in an organic phase (kerosene) at interfacial tensions not lower than $4 \mathrm{mN} / \mathrm{m}$ was observed, which was assisted by the presence of reverse micelles in the kerosene. Usually, spontaneous emulsification is associated in microemulsions with ultra-low interfacial tensions as the main characteristic of this process. Thus, it was shown that spontaneous emulsification can also be driven by the solubilisation of water molecules inside the swollen reverse micelles. The size of the microemulsion droplet (or swollen micelles) was found in the range of $200 \mathrm{~nm}$.

The swollen micelles present in the organic phase make the organic phase cloudy, which proves the presence of aqueous droplets in the system. It is shown also that the presence of salt in the aqueous phase inhibits microdroplet formation. Sessile aqueous droplets placed inside the kerosene phase were dissolved in kerosene through formation and growth of droplets, which form an aqueous film at the droplet base.

\section{Acknowledgements}

This work was supported by CoWet Marie Curie Intra-European Fellowship within the 7th European Community Framework Programme; MAP EVAPORATION project, European Space Agency and COST MP 1106 EU project. 


\section{References}

1. Lopez-Montilla, J.C., P.E. Herrera-Morales, S. Pandey, and D.O. Shah, Spontaneous emulsification: Mechanisms, physicochemical aspects, modeling, and applications. Journal of Dispersion Science and Technology, 2002. 23(1-3): p. 219-268.

2. Bermúdez-Salguero, C. and J. Gracia-Fadrique, Analysis of Gibbs adsorption equation and thermodynamic relation between Gibbs standard energies of adsorption and micellization through a surface equation of state. Journal of Colloid and Interface Science, 2011. 355(2): p. 518-519.

3. Miller, C.A., Spontaneous emulsification produced by diffusion - a review. Colloids and Surfaces, 1988. 29(1): p. 89-102.

4. Davies, J.T. and D.A. Haydon. Proceedings of the Second International Congress of Surface Activity. London: Butterworths.

5. Quintanar-Guerrero, D., E. Allémann, E. Doelker, and H. Fessi, A mechanistic study of the formation of polymer nanoparticles by the emulsification-diffusion technique. Colloid and Polymer Science. 275(7): p. 640-647.

6. Shahidzadeh, N., D. Bonn, and J. Meunier, A new mechanism of spontaneous emulsification: Relation to surfactant properties. Europhysics Letters, 1997. 40(4): p. 459-464.

7. Kunieda, H., Y. Fukui, H. Uchiyama, and C. Solans, Spontaneous formation of highly concentrated water-in-oil emulsions (gel-emulsions). Langmuir, 1996. 12(9): p. 21362140.

8. Forgiarini, A., J. Esquena, C. Gonzalez, and C. Solans, Formation of nano-emulsions by low-energy emulsification methods at constant temperature. Langmuir, 2001. 17(7): p. 2076-2083. 
9. Greiner, R.W. and D.F. Evans, Spontaneous formation of a water-continuous emulsion from a w/o microemulsion. Langmuir, 1990. 6(12): p. 1793-1796.

10. Atkins, P. and J. de Paula, Atkins' Physical Chemistry2010: OUP Oxford.

11. Shinoda, K. and H. Kunieda, Conditions to produce so-called microemulsions factors to increase mutual solubility of oil and water by solubilizer. Journal of Colloid and Interface Science, 1973. 42(2): p. 381-387.

12. Shinoda, K. and S. Friberg, Microemulsions - colloidal aspects. Advances in Colloid and Interface Science, 1975. 4(4): p. 281-300.

13. Oliveira, M.B., J.A.P. Coutinho, and A.J. Queimada, Mutual solubilities of hydrocarbons and water with the CPA EoS. Fluid Phase Equilibria, 2007. 258(1): p. $58-66$.

14. Pereda, S., J.A. Awan, A.H. Mohammadi, A. Valtz, C. Coquelet, E.A. Brignole, and D. Richon, Solubility of hydrocarbons in water: Experimental measurements and modeling using a group contribution with association equation of state (GCA-EoS). Fluid Phase Equilibria, 2009. 275(1): p. 52-59.

15. Bouchemal, K., S. Briançon, E. Perrier, and H. Fessi, Nano-emulsion formulation using spontaneous emulsification: solvent, oil and surfactant optimisation. International Journal of Pharmaceutics, 2004. 280(1-2): p. 241-251.

16. Fahd, M.E.A., Y. Wenming, P.S. Lee, S.K. Chou, and C.R. Yap, Experimental investigation of the performance and emission characteristics of direct injection diesel engine by water emulsion diesel under varying engine load condition. Applied Energy, 2013. 102: p. 1042-1049.

17. Armas, O., R. Ballesteros, F.J. Martos, and J.R. Agudelo, Characterization of light duty Diesel engine pollutant emissions using water-emulsified fuel. Fuel, 2005. 84(78): p. 1011-1018. 
18. Dragosavac, M.M., G.T. Vladisavljević, R.G. Holdich, and M.T. Stillwell, Production of Porous Silica Microparticles by Membrane Emulsification. Langmuir, 2012. 28(1): p. 134-143.

19. Kitamura, Y., Q. Huang, A. Miyachi, K. Yoshizako, and T. Takahashi, Effect of temperature on interfacial tension in kerosene-surfactant-water systems. Journal of Colloid and Interface Science, 1992. 154(1): p. 249-254.

20. Peltonen, L.J. and J. Yliruusi, Surface Pressure, Hysteresis, Interfacial Tension, and CMC of Four Sorbitan Monoesters at Water-Air, Water-Hexane, and Hexane-Air Interfaces. Journal of Colloid and Interface Science, 2000. 227(1): p. 1-6.

21. Emberson, D.R., B. Ihracska, S. Imran, and A. Diez, Optical characterization of Diesel and water emulsion fuel injection sprays using shadowgraphy. Fuel, 2016. 172: p. 253-262. 


\title{
Spontaneous Emulsification of Water in Oil at Appreciable Interfacial Tensions
}

Pedro S. Silva ${ }^{1 \mathrm{a}}$, Sergey Zhdanov ${ }^{2 \mathrm{~b}}$, Victor M. Starov ${ }^{1 \mathrm{c}}$, Richard G. Holdich ${ }^{1 * \mathrm{~d}}$

${ }^{1}$ Department of Chemical Engineering, Loughborough University, Loughborough, LE11 3TU, UK.

${ }^{2}$ Micropore Technologies Ltd, T-366, Wilton Centre, Redcar, TS10 4RF

ap.t.santos-silva@lboro.ac.uk, bs.zhdanov@micropore.co.uk, cv.m.starov@lboro.ac.uk, ${ }^{\mathrm{d}}$ r.g.hodich@lboro.ac.uk

\begin{abstract}
Spontaneous formation of aqueous droplets in kerosene was observed, which was facilitated by the presence of an oil soluble surfactant: $\operatorname{Span}^{\circledR} 80$ at concentrations above CMC. Kerosene/water interfacial tension under all conditions studied was not lower than 4 $\mathrm{mN} / \mathrm{m}$. Therefore, ultra-low interfacial tension was not required for this process to occur spontaneously. The process was caused by a transfer of water molecules to swollen reversed micelles. The influence of both the surfactant concentration in the organic phase and $\mathrm{NaCl}$ concentration in the aqueous phase on spontaneous aqueous droplet formation was investigated. Nano-sizing analyse of the drops was performed, which showed the droplets sizes in between 100 and $400 \mathrm{~nm}$. It is proven that the presence of salt in the aqueous phase inhibits droplet formation. It is shown that big sessile aqueous droplets deposited on a hydrophobic substrate inside the kerosene phase were dissolved in kerosene through formation and growth of droplets, which form an aqueous film at the droplet base.
\end{abstract}


Key words: spontaneous emulsification, w/o emulsions, interfacial tension, $\operatorname{Span}^{\circledR} 80$.

\section{Introduction}

Emulsions consist of a discontinuous phase (droplets), a continuous phase (liquid surrounding the droplets) and an interface where surfactants are usually present, lowering the interfacial tension and, therefore, decreasing the free energy for formation and stabilizing the two phase system. Energy input is required, generally mechanical, to disperse the discontinuous phase in the continuous phase and to create the additional interfacial area. The Gibbs free energy increase of the system $(\Delta \mathrm{G})$, at constant composition and pressure after mixing is as follows:

$$
\Delta G=\gamma \Delta A-T \cdot \Delta S
$$

where $\Delta \mathrm{S}$ is an entropy increase, $\Delta \mathrm{A}$ is the increase of the interface, $\mathrm{T}$ is temperature in Kelvin and $\gamma$ is an interfacial tension.

For the spontaneous formation of emulsions $\Delta \mathrm{G}$ should be negative, hence, the interfacial tension $(\gamma)$ should is very low [1].

The extent of surfactant adsorption at a liquid surface is expressed in terms of its surface excess concentration, $\Gamma$. Surface excess concentration is related to surface tension by the Gibbs equation, which for a non-ionic surfactant takes the form [2]:

$$
\Gamma=-\frac{c}{R T} \frac{d \gamma}{d c}=-\frac{1}{R T}\left(\frac{d \gamma}{d \ln c}\right) s
$$

where $\mathrm{c}$ is the surfactant concentration. It becomes possible to estimate the area occupied by each adsorbed surfactant molecule at known $\Gamma[2]$.

Microemulsions are an example of thermodynamically stable and macroscopically homogeneous mixtures of water, oil and surfactant. They form spontaneously and they are characterised by ultra-low interfacial tension $(<0.1 \mathrm{mN} / \mathrm{m})$ between water and oil, thus 
minimising the required amount of energy to form the new surface area as shown in Eq (1). Microemulsions can be opaque or transparent depending on the size and concentration of droplets in the emulsion. In the case of ultralow interfacial tension this type of emulsification does not require energy input, as the ultralow interfacial tension leads to a spontaneous emulsification when the phases are brought in contact [1]. The full mechanism behind this phenomenon is still under investigation and is a matter for discussion despite the fact that microemulsions were first recorded in the XIX century [3-10].

Spontaneous formation of a new type of emulsions in the presence of relatively high surfactant concentration and high enough interfacial tension was earlier discovered [11]. According to Shinoda and Kunieda [11] this systems were erroneously considered as microemulsions, however, they are "solubilized solutions" and for such systems "swollen micellar solution" may be a more adequate term [11]. Usually, very large concentrations (10$25 \% \mathrm{w} / \mathrm{w}$ ) of a non-ionic surfactant are required to produce these so-called microemulsions $[11,12]$. Solubility of water in hydrocarbons and vice versa has been studied extensively due to the high interest that energy industry has. Equations of state have been used to describe mutual solubility of water and several types of hydrocarbons in a wide range of pressures and temperature $[13,14]$.

Below spontaneous formation of water in oil (w/o) emulsion, at sufficiently high interfacial tension in the presence of high concentration of oil soluble surfactant is investigated. From the very beginning it was understood that such microemulsions are actually swollen reverse micelles [11].

Control of spontaneous emulsification might be important in a number of applications where there is a demand for nano-sized droplets in an emulsion such as in personal care, cosmetics and health, care industry [15]. Alternatively, this process might be undesirable. An excess of surfactant is commonly used in a semi-batch process where the amount of disperse 
phase increases with time and an "over use" of surfactant takes places in order to avoid the depletion of surfactant at the end of the process. The existence of this spontaneous process should be taken in to consideration in processes where the main goal is to have great control over the droplet size and size distribution (e.g. in membrane emulsification). Processes operated over a long period of time can be more vulnerable.

An interesting possible application of spontaneous microemulsions is the fuel industry, there is an interest in (w/o) emulsions, which can play a substantial role in reducing emissions and improving engine performance: diesel fuel emulsions have been shown to reduce $\mathrm{NO}_{\mathrm{x}}$, $\mathrm{CO}$, soot, hydrocarbons and particulate matter emissions when used in a compression ignition engine [16], and better overall efficiency [17]. In the production of uniform particles there are a number of w/o processes where hydrogel particles are formed by dispersing an aqueous phase into an oil phase, typically low odour kerosene, using membrane emulsification to form uniform droplets and, therefore, particles after reaction [18]. This reaction is often a condensation polymerisation in which water is one of the reaction products, thus nano-sized emulsion drops become evident during the reaction often detected as a cloudy haze.

The spontaneous process reported below was performed using sessile droplet experiments where a single big water drop (surrounded by the organic phase) was monitored. In order to confirm the presence of aqueous nano-droplets in the organic phase, with a varying concentration of oil soluble surfactant, a set of experiments were designed to evaluate the drop size and concentration at equilibrium conditions using a nano-droplet tracking analysis characterisation technique. Kerosene was chosen as the organic phase because it is both an example of a common fuel and it is used in a number of emulsification processes [18] for hydrogel particles. 


\section{Materials and methods}

Sessile droplet experiments were carried out to monitor time evolution of aqueous droplet height, radius and dynamic contact angle. The experiments were performed using a custom-built experimental setup, which is presented in Figure 1. The substrate used was a 316 stainless steel (SS) sheet $(0.1 \times 25 \times 25 \mathrm{~mm})$ purchased from GoodFellow Ltd. The substrates were chemically hydrophobically coated. The cleaning of the substrate consisted of placing the SS sheets in an organic solvent (methanol and/or acetone) followed by drying at $40-50^{\circ} \mathrm{C}$ for at least 30 minutes before the start of a new experiment. A DMK 23G $445 \mathrm{GigE}$ monochrome industrial camera (Imaging source, Germany), coupled with Bi-telecentric lenses (OPTO Engineering, Italy), was used for monitoring the side view of the droplet. On the opposite side a light source was mounted parallel to the camera - telecentric HP Illuminator (OPTO Engineering, Italy) as shown schematically in Figure 1.

The experimental protocol was as follows: a water droplet was deposited on the hydrophobic SS sheet which was surrounded by the organic phase (kerosene). The volume used of organic phase was about $20 \mathrm{~mL}$, contained in a glass chamber of 40x40x30 mm. During experiments the chamber was covered in order to avoid dust deposition. The drop deposition was performed using a micro-syringe $(500 \mu \mathrm{L})$ mounted in a support designed to improve the drop placement accuracy.

The organic phase was low odour kerosene purchased from Sigma Aldrich. The surfactant $\operatorname{Span}^{\circledR} 80$, purchased from Sigma Aldrich, was dissolved in the organic phase. This surfactant includes a sorbitol group (hydrophilic head) and a long unsaturated carbon chain (hydrophobic tail) and is commonly used to stabilise w/o emulsions. Its chemical structure is shown in Figure 2. 


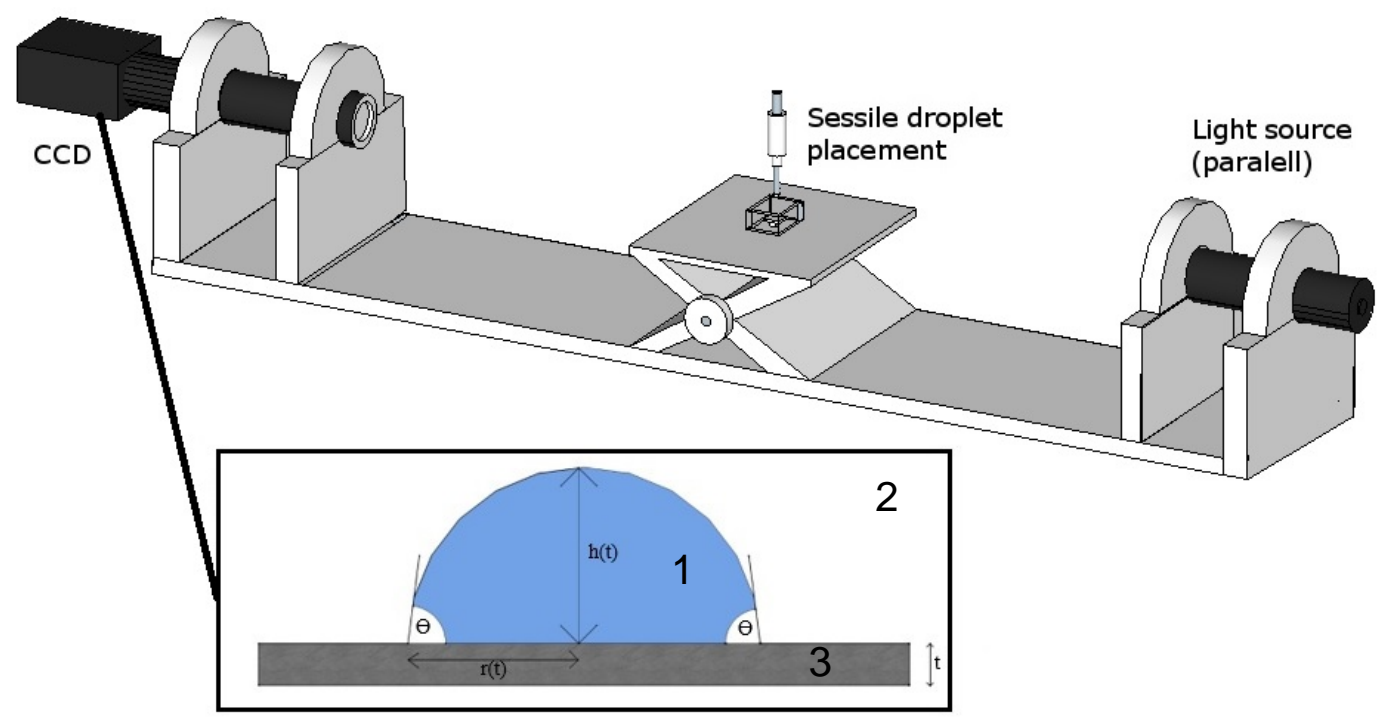

Figure 1. Diagram of the experimental set up for sessile droplet experiments: 1 - aqueous droplet with (or without) added salt; 2 - organic phase with (or without) Span ${ }^{\circledR} 80$ surfactant, 3 - hydrophobic support

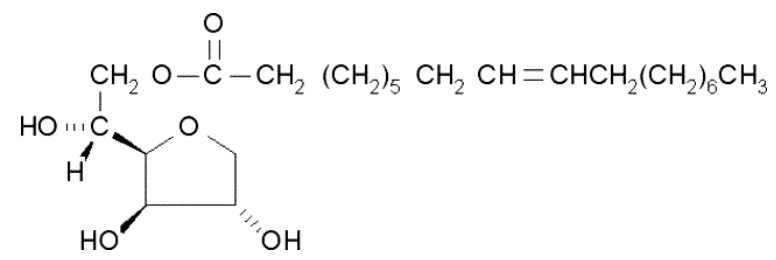

Figure 2. The chemical structure of surfactant $\operatorname{Span}{ }^{\circledR} 80$

Image analysis was undertaken using a computer application of Vision Builder from LabView (National Instruments). The software was designed to acquire the following measurements of the droplet: height $(\mathrm{h})$, contact angle $(\Theta)$ and radius $(\mathrm{r})$ of the droplet base. So the drop volume (V) could be determined using well-known equations (3) or (4). The two equations allow calculating the droplet volume in two different ways. These two different ways of calculation of the drop volume were compared in order to evaluate the image analysis reliability, estimating the measurement error. The drop volume was normalised according to Eq. (5). The droplet was formed in the organic phase with surfactant (Figure 1). 
Various amounts of surfactant used in the system changed the interfacial tension, up to the Critical Micelle Concentration (CMC). However, the spontaneous droplet formation was observed only at concentration above CMC, which resulted in different droplet sizes.

Drop volume was determined using measured values of height (h) and radius of the base (r):

$$
V=\frac{\pi h}{24}\left(3 r^{2}+h^{2}\right)
$$

Alternatively the drop volume was also determined using measured values of the radius of the base $(r)$ and contact angle $(\Theta)$ :

$$
V=\frac{\pi r^{3}}{3}\left(\frac{2-3 \cos (\theta)+\cos ^{3}(\theta)}{\sin ^{3} \theta}\right)
$$

The reduced droplet volume was calculated according to the following equation:

$$
V_{n}=\frac{V(t)}{V_{0}}
$$

Additional to the sessile droplets experiments, another procedure was used in order to gain extra information on the system under investigation. Six solutions of an aqueous phase with different $\mathrm{NaCl}$ concentrations $(0 \%, 0.1 \%, 1 \%, 2 \%, 5 \%$ and $10 \% \mathrm{w} / \mathrm{w})$ and four kerosene solutions with different $\operatorname{Span}^{\circledR} 80$ concentrations were prepared. In each $10 \mathrm{~mL}$ of kerosene Span $^{\circledR} 80$ solutions were added to $10 \mathrm{~mL}$ of aqueous $\mathrm{NaCL}$ solutions and left undisturbed in hermetically closed vials (clear glass $28 \mathrm{~mL}$ capacity) for several hours. In total 24 vials were prepared in such a way. After reaching equilibrium by both phases the presence of water droplets in the organic phase was checked, and the concentration and size of droplets were determined using a NanoSight LM10 (NanoSight/Malvern, Amerbury, United Kingdom), equipped with a sample chamber with a 640-nm laser and a Viton fluroelastomer O-ring. The device was using Nano-particle Tracking Analysis (NTA) software. The samples were injected in to the sample chamber with sterile $(5 \mathrm{~mL})$ plastic syringes (BD Discardit ${ }^{\circledR}$ II) until 
the liquid reached the tip of the nozzle. All measurements were carried out at room temperature $25^{0}$ C. NTA 3.0 software was used for capturing and analysing the data. Samples were measured for 60 seconds with manual shutter and gain adjustments. Five measurements of each sample were repeated and the averaged values were used.

Interfacial tension measurements were carried out using the DCAT11 tensiometer from DataPhysics using the Wilhelmy-plate method. Prior to each measurement, the platinum plate was cleaned using a burner to remove all organic traces. To determine the CMC the surfactant concentration in the kerosene was subsequently increased while measuring interfacial tension between the kerosene and pure water.

\section{Results and discussion}

\subsection{Characterization of the water droplets present in the organic phase}

The influence of both salt concentration in the aqueous phase and surfactant concentration of $\operatorname{Span}{ }^{\circledR} 80$ in the organic phase of spontaneous formation of aqueous droplets in kerosene was investigated.

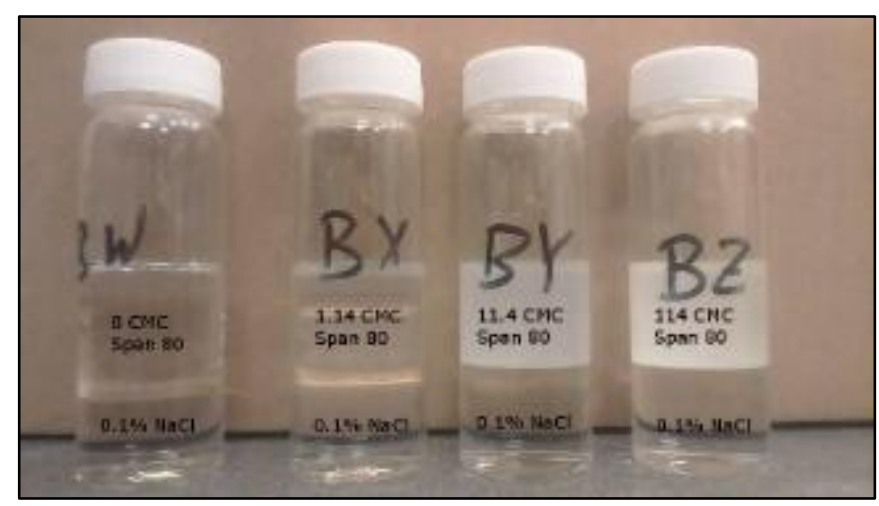

Figure 3. Example of the surfactant concentration influence on the self-emulsification process: each vial contains $10 \mathrm{~mL}$ of water (lower liquid layer) and $10 \mathrm{~mL}$ of kerosene (top liquid layer) with different concentration of $\mathrm{Span}^{\circledR}$ 80: samples BW, BX, BY and BZ contain pure water, 1.14, 11.4 and 114 times the CMC, respectively. There is no visible detection of microemulsion formation in vials BW and BX, but they are present in vials BY and BZ. 
Figure 3 shows that microemulsions were formed only if the concentration of micelles in the kerosene was higher than some critical value, which is according to our experimental results either equal to $\mathrm{CMC}$ or slightly above $\mathrm{CMC}$. Observations performed during the experiments indicated that the turbidity in the organic phase was clearly influenced by the amount of surfactant present (Figure 3). Influence of salt concentration in the aqueous phase on the microemulsion formation was also investigated. These experiments proved that the higher salt concentration in the aqueous phase the lower turbidity becomes (or low concentration of droplets inside the kerosene). Below characterization of this process was carried out, using NTA size analysis: concentration of the aqueous microdroplets and their size was determined.

Tables 1 and 2 summarise the data collected from these experiments. Higher concentration of surfactant promotes the self-emulsification of water in kerosene, while higher concentration of salt retards, or even stops, this phenomenon from happening.

Table 1 Droplet concentration with salt and surfactant concentration on the spontaneous formation of aqueous droplets in kerosene

\begin{tabular}{|c|c|c|c|c|}
\hline $\begin{array}{c}\text { Concentration of } \\
\mathrm{NaCl}\end{array}$ & \multicolumn{5}{|c|}{ Concentration of drops (number/mL) at the following CMC values: } \\
\hline$(\% \mathbf{w} / \mathbf{w})$ & $\mathbf{0 x}$ & $\mathbf{1 . 1 4 \times}$ & $\mathbf{1 1 . 4 \times}$ & $\mathbf{1 1 4 x}$ \\
\hline 0 & 0 & $6.0 \times 10^{8}$ & $2.5 \times 10^{12}$ & $7.0 \times 10^{12}$ \\
\hline 0.1 & 0 & 0 & $1.19 \times 10^{12}$ & $3.5 \times 10^{12}$ \\
\hline 1 & 0 & 0 & $2.7 \times 10^{8}$ & $1.9 \times 10^{11}$ \\
\hline 2 & 0 & 0 & $7.6 \times 10^{8}$ & $1.2 \times 10^{11}$ \\
\hline 5 & 0 & 0 & $7.05 \times 10^{8}$ & $9.1 \times 10^{10}$ \\
\hline 10 & 0 & 0 & $2.5 \times 10^{8}$ & $1.1 \times 10^{10}$ \\
\hline
\end{tabular}


Table 2. Aqueous droplet size with salt concentration in the aqueous phase and surfactant concentration in the organic phase

\begin{tabular}{|c|c|c|c|c|}
\hline $\begin{array}{c}\text { Concentration of } \\
\mathrm{NaCl}\end{array}$ & \multicolumn{5}{|c|}{ Drop size (nm) at the following CMC values: } \\
\hline$(\% \mathbf{w} / \mathbf{w})$ & $\mathbf{0 x}$ & $\mathbf{1 . 1 4 x}$ & $\mathbf{1 1 . 4 x}$ & $\mathbf{1 1 4 x}$ \\
\hline 0 & 0 & 226 & 190 & 320 \\
\hline 0.1 & 0 & 0 & 190 & 290 \\
\hline 1 & 0 & 0 & 230 & 210 \\
\hline 2 & 0 & 0 & 210 & 270 \\
\hline 5 & 0 & 0 & 220 & 240 \\
\hline 10 & 0 & 0 & 420 & \\
\hline
\end{tabular}

The data presented in Table 1 shows that the concentration of drops formed in the organic phase decreases rapidly with increasing of salt concentration. In the absence of any salt in the aqueous phase the maximum water drop concentration reaches $7.0 \times 10^{12}$ drops per $\mathrm{mL}$, when using a Span 80 concentration 114 times that of the CMC value. Table 2 illustrates a wide range of droplet sizes found in the samples that contained aqueous droplets in the organic phase, but the reported drop sizes are generally between 200 and 300 nanometres.

The data suggests that self-emulsification does not occur when the surfactant concentration is below the $\mathrm{CMC}$ and that even a very low concentration of salt will stop the self-emulsification process when operating at a surfactant concentration close to the CMC. When operating at a surfactant concentration of 114 times CMC then 200 to 300 nanometre aqueous drops were formed at all concentrations of salt used in the aqueous phase, but with much reduced resulting drop concentration at increasing salt concentration. 


\subsection{Sessile droplets experiments}

According to the procedure described above (two ways of calculations of the droplet volume) the experimental error in the drop volume calculations is less than $7 \%$. Experiments on time evolution of aqueous droplets deposited on a hydrophobic substrate surrounded by an organic phase (kerosene) with a high amount of surfactant $\left(\operatorname{Span}^{\circledR} 80\right)$ in the organic phase are reported in this section. The concentration of surfactant used was 114 times above the CMC. 5 seconds after placing the water drop on the hydrophobic substrate (SS), some cloudiness was observed at the bottom of the droplet (Figure 4a). After 125 seconds (Figure $4 \mathrm{~b})$, the cloudiness became more visible and a film started to form on the substrate in the vicinity of the three phase contact line. After around 1 hour (Figure 4d), the film became large enough to be observed using the top camera. The film had a circular shape around the droplet base and its diameter increased with time. It was observed after $8 \mathrm{~h}$ that the main droplet was becoming noticeably smaller and the film thicker with time. Hence, during this experiment spontaneous emulsification was happening over a prolonged period of time, transferring water from the main drop to the surrounding film via microemulsion droplets within the continuous phase (kerosene).

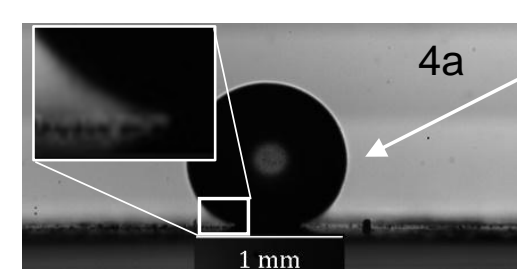

$\mathrm{t}_{1}=5 \mathrm{~s}$

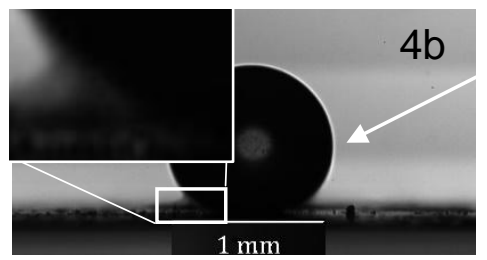

$\mathrm{t}_{2}=125 \mathrm{~s}$

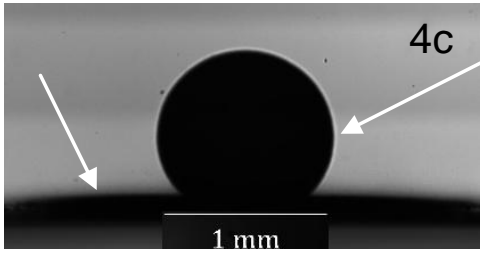

$\mathrm{t}_{3}=1 \mathrm{~h}$ 


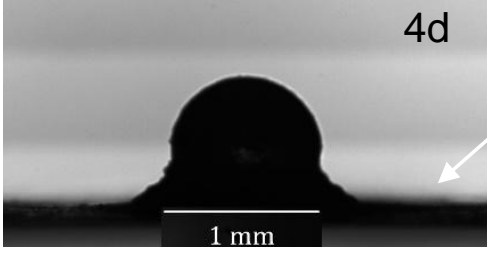

$\mathrm{t}_{4}=8 \mathrm{~h}$

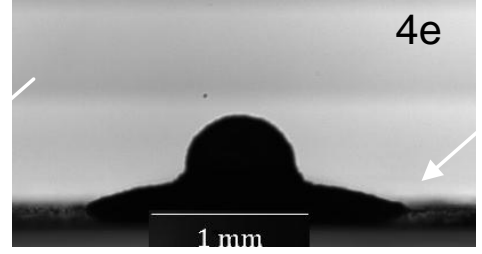

$\mathrm{t}_{5}=22 \mathrm{~h}$

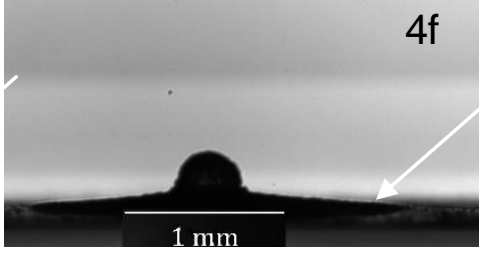

$\mathrm{t}_{6}=48 \mathrm{~h}$

Figure 4. Formation of a cloud of nano-sized droplets and a film at the droplet base assisted by swollen micelles present in the organic phase (kerosene)

The critical micelle concentration of $\mathrm{Span}^{\circledR} 80$ in kerosene was determined by interfacial tension measurements, and found to be $0.51 \pm 0.07 \mathrm{mM}$. The interfacial tension between water and kerosene at the $\mathrm{CMC}$ is $4.0 \pm 0.1 \mathrm{mN} / \mathrm{m}$. This value agrees well with the literature data [19]. According to Peltonen measurements [20] this surfactant apparently has higher interfacial tension at the CMC using a pure alkane (hexane) instead of a mixture of alkanes and some residual aromatics hydrocarbons present in the low odour kerosene.

The water drop volume behaviour for four different $\operatorname{Span}^{\circledR} 80$ concentrations was also investigated. The phenomenon described above (film formation around the droplet base) was only observed when $\operatorname{Span}^{\circledR} 80$ concentrations used was above 11.4 CMC. After a certain time contact angle could not be measured anymore due to the presence of the surrounding water film. Therefore, the volume on time dependences presented in Figure 5 were determined using just the height of the droplet and assuming that radius of the droplet was constant.

It can be seen in Figure 5 that the decrease of the drop volume is faster when the number of micelles in the organic phase is higher. This implies that the mass transfer of water in the organic phase is influenced by the presence of reverse micelles. The decrease of volume of aqueous droplet shows a linear behaviour when surfactant is not present in organic phase. The rate $(\mathrm{dV} / \mathrm{dt})$ determined is this case was $1.8 \mathrm{~nL} / \mathrm{h}$. However, in presence of 
surfactants above the critical concentration (11.4 and 114 times its $\mathrm{CMC}$ ), the water drop volume decreases logarithmically.

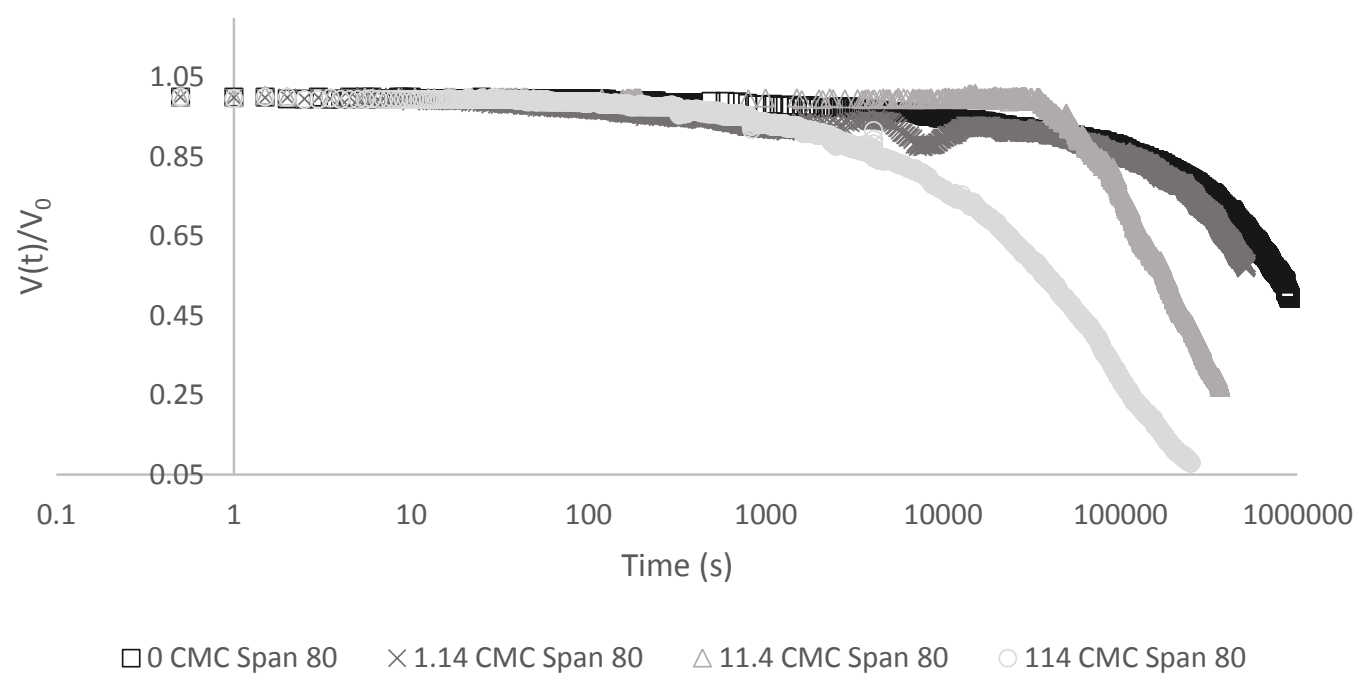

Figure 5. Influence of surfactant concentration on the water sessile droplet solubilisation in to the surrounding phase

In this system the reverse micelles solubilise water molecules and transfer through the organic phase. The micelles swell over time and, eventually become large enough to scatter light and to sink to form the film of water around the main water drop. The process is shown schematically in Figure 6.

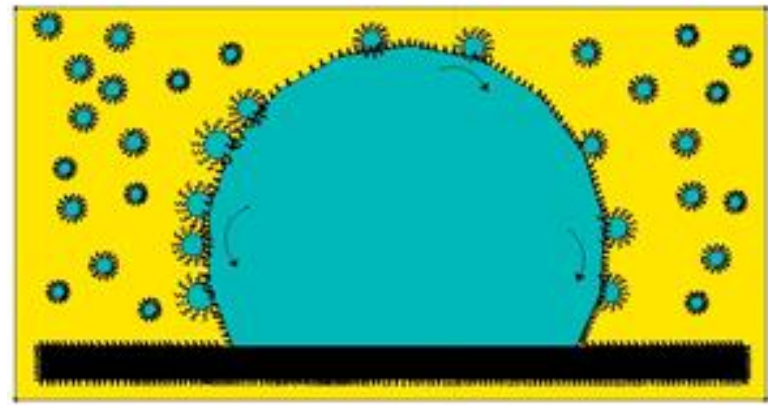


Figure 6. Schematic representation of spontaneous emulsification being driven by the swollen micelles

As soon as the water molecules "escape" from the droplet they are surrounded by the micelles which solubilise them and swell. Due to the buoyancy effect, these swollen micelles roll down to the bottom forming a film. Different salt concentrations were tested in the aqueous phase. According to part 3.1 the increased salt concentration should inhibit the mass transfer of water into the organic phase. A range of $\mathrm{NaCl}$ concentrations in the aqueous drop was investigated, the results are shown in Figure 7.

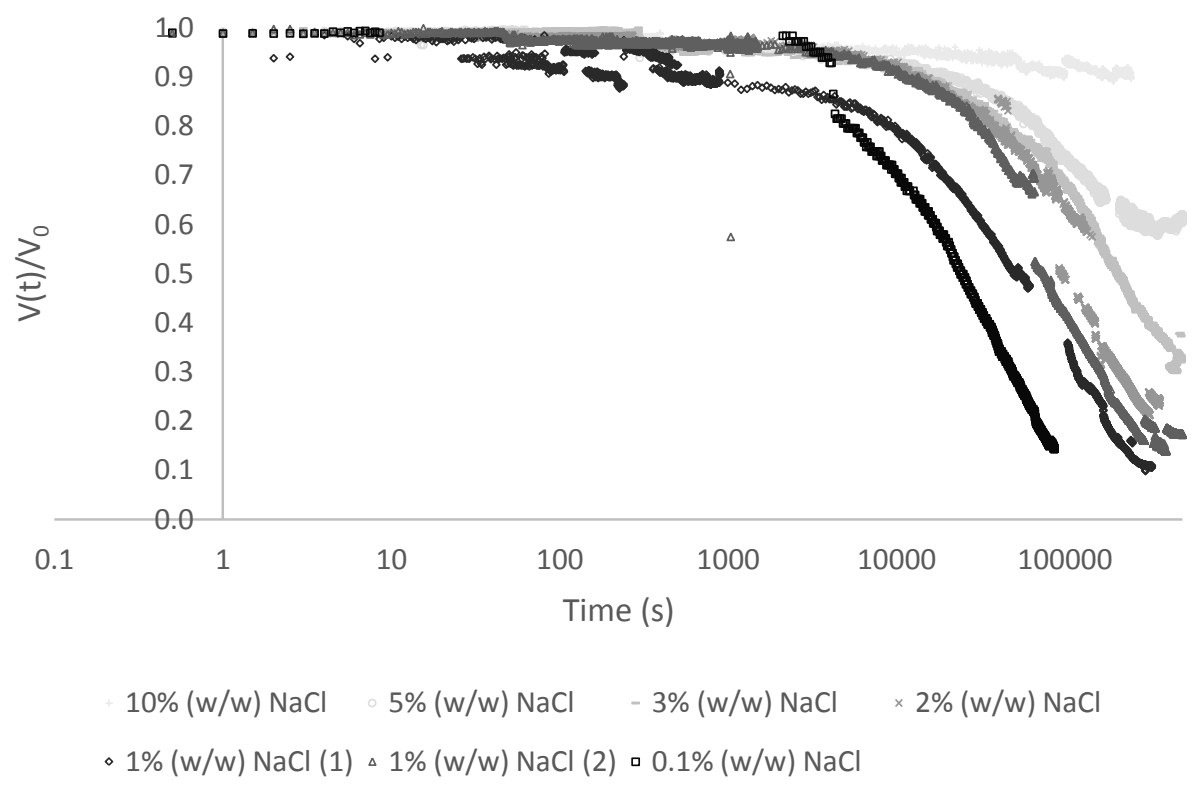

Figure 7. Influence of salt in the aqueous phase on the drop volume evolution

Figure 7 shows that different concentrations of $\mathrm{NaCl}$ in the water phase have a clear influence on the transfer of water molecules to swollen micelles. Higher concentrations of salt slow down the transfer process. At a concentration of $10 \%(\mathrm{w} / \mathrm{w}) \mathrm{NaCl}$ the droplet barely changes its volume for almost 250000 seconds (70 hours). It is important to note that during 
mass transfer the salt concentration in the water droplet increases over time which explains the non-linear behaviour of the droplet volume shrinking with time for lower ratios of CMC.

\section{Conclusions}

Spontaneous formation of aqueous microdroplet in an organic phase (kerosene) at interfacial tensions not lower than $4 \mathrm{mN} / \mathrm{m}$ was observed, which was assisted by the presence of reverse micelles in the kerosene. Usually, spontaneous emulsification is associated in microemulsions with ultra-low interfacial tensions as the main characteristic of this process. Thus, it was shown that spontaneous emulsification can also be driven by the solubilisation of water molecules inside the swollen reverse micelles. The size of the microemulsion droplet (or swollen micelles) was found in the range of $200 \mathrm{~nm}$.

The swollen micelles present in the organic phase make the organic phase cloudy, which proves the presence of aqueous droplets in the system. It is shown also that the presence of salt in the aqueous phase inhibits microdroplet formation. Sessile aqueous droplets placed inside the kerosene phase were dissolved in kerosene through formation and growth of droplets, which form an aqueous film at the droplet base.

\section{Acknowledgements}

This work was supported by CoWet Marie Curie Intra-European Fellowship within the 7th European Community Framework Programme; MAP EVAPORATION project, European Space Agency and COST MP 1106 EU project. 


\section{References}

1. Lopez-Montilla, J.C., P.E. Herrera-Morales, S. Pandey, and D.O. Shah, Spontaneous emulsification: Mechanisms, physicochemical aspects, modeling, and applications. Journal of Dispersion Science and Technology, 2002. 23(1-3): p. 219-268.

2. Bermúdez-Salguero, C. and J. Gracia-Fadrique, Analysis of Gibbs adsorption equation and thermodynamic relation between Gibbs standard energies of adsorption and micellization through a surface equation of state. Journal of Colloid and Interface Science, 2011. 355(2): p. 518-519.

3. Miller, C.A., Spontaneous emulsification produced by diffusion - a review. Colloids and Surfaces, 1988. 29(1): p. 89-102.

4. Davies, J.T. and D.A. Haydon. Proceedings of the Second International Congress of Surface Activity. London: Butterworths, 1957.

5. Quintanar-Guerrero, D., E. Allémann, E. Doelker, and H. Fessi, A mechanistic study of the formation of polymer nanoparticles by the emulsification-diffusion technique. Colloid and Polymer Science, 1997. 275(7): p. 640-647.

6. Shahidzadeh, N., D. Bonn, and J. Meunier, A new mechanism of spontaneous emulsification: Relation to surfactant properties. Europhysics Letters, 1997. 40(4): p. 459-464.

7. Kunieda, H., Y. Fukui, H. Uchiyama, and C. Solans, Spontaneous formation of highly concentrated water-in-oil emulsions (gel-emulsions). Langmuir, 1996. 12(9): p. 21362140.

8. Forgiarini, A., J. Esquena, C. Gonzalez, and C. Solans, Formation of nano-emulsions by low-energy emulsification methods at constant temperature. Langmuir, 2001. 17(7): p. 2076-2083. 
9. Greiner, R.W. and D.F. Evans, Spontaneous formation of a water-continuous emulsion from a w/o microemulsion. Langmuir, 1990. 6(12): p. 1793-1796.

10. Atkins, P. and J. de Paula, Atkins' Physical Chemistry2010: OUP Oxford.

11. Shinoda, K. and H. Kunieda, Conditions to produce so-called microemulsions factors to increase mutual solubility of oil and water by solubilizer. Journal of Colloid and Interface Science, 1973. 42(2): p. 381-387.

12. Shinoda, K. and S. Friberg, Microemulsions - colloidal aspects. Advances in Colloid and Interface Science, 1975. 4(4): p. 281-300.

13. Oliveira, M.B., J.A.P. Coutinho, and A.J. Queimada, Mutual solubilities of hydrocarbons and water with the CPA EoS. Fluid Phase Equilibria, 2007. 258(1): p. $58-66$.

14. Pereda, S., J.A. Awan, A.H. Mohammadi, A. Valtz, C. Coquelet, E.A. Brignole, and D. Richon, Solubility of hydrocarbons in water: Experimental measurements and modeling using a group contribution with association equation of state (GCA-EoS). Fluid Phase Equilibria, 2009. 275(1): p. 52-59.

15. Bouchemal, K., S. Briançon, E. Perrier, and H. Fessi, Nano-emulsion formulation using spontaneous emulsification: solvent, oil and surfactant optimisation. International Journal of Pharmaceutics, 2004. 280(1-2): p. 241-251.

16. Fahd, M.E.A., Y. Wenming, P.S. Lee, S.K. Chou, and C.R. Yap, Experimental investigation of the performance and emission characteristics of direct injection diesel engine by water emulsion diesel under varying engine load condition. Applied Energy, 2013. 102: p. 1042-1049.

17. Armas, O., R. Ballesteros, F.J. Martos, and J.R. Agudelo, Characterization of light duty Diesel engine pollutant emissions using water-emulsified fuel. Fuel, 2005. 84(78): p. 1011-1018. 
18. Dragosavac, M.M., G.T. Vladisavljević, R.G. Holdich, and M.T. Stillwell, Production of Porous Silica Microparticles by Membrane Emulsification. Langmuir, 2012. 28(1): p. 134-143.

19. Kitamura, Y., Q. Huang, A. Miyachi, K. Yoshizako, and T. Takahashi, Effect of temperature on interfacial tension in kerosene-surfactant-water systems. Journal of Colloid and Interface Science, 1992. 154(1): p. 249-254.

20. Peltonen, L.J. and J. Yliruusi, Surface Pressure, Hysteresis, Interfacial Tension, and CMC of Four Sorbitan Monoesters at Water-Air, Water-Hexane, and Hexane-Air Interfaces. Journal of Colloid and Interface Science, 2000. 227(1): p. 1-6.

21. Emberson, D.R., B. Ihracska, S. Imran, and A. Diez, Optical characterization of Diesel and water emulsion fuel injection sprays using shadowgraphy. Fuel, 2016. 172: p. 253-262. 
Spontaneous formation of aqueous droplets in kerosene was observed, which was facilitated by the presence of an oil soluble surfactant: $\operatorname{Span}^{\circledR} 80$ at concentrations above CMC. Kerosene/water interfacial tension under all conditions studied was not lower than 4 $\mathrm{mN} / \mathrm{m}$. Therefore, ultra-low interfacial tension was not required for this process to occur spontaneously. The process was caused by a transfer of water molecules to swollen reversed micelles. The influence of both the surfactant concentration in the organic phase and $\mathrm{NaCl}$ concentration in the aqueous phase on spontaneous aqueous droplet formation was investigated. Nano-sizing analyse of the drops was performed, which showed the droplets sizes in between 100 and $400 \mathrm{~nm}$. It is proven that the presence of salt in the aqueous phase inhibits droplet formation. It is shown that big sessile aqueous droplets deposited on a hydrophobic substrate inside the kerosene phase were dissolved in kerosene through formation and growth of droplets, which form an aqueous film at the droplet base. 